\title{
MEdeiros, M. (ED.) (2016). Fotogramas. ENSAios SObRe fotografia. Lisboa: Sistema Solar.
}

\author{
Joana Bicacro
}

Fotogramas, publicado em 2016 pela Sistema Solar, reúne um conjunto de estudos sobre fotografia, arquivo e memória, resultantes do colóquio A Fotografia na era da pósfotografia, que decorreu na Faculdade de Ciências Sociais e Humanas da Universidade Nova de Lisboa em 2012. Entre a história, a crítica da cultura ou a arqueologia dos meios, Fotogramas pretende iluminar recantos do passado esquecido dos meios fotográficos e, ao mesmo tempo, constituir uma alternativa os grandes empreendimentos enciclopédicos e sistemáticos, que circunscrevem a fotografia aos usos historiográficos oficiais. Margarida Medeiros, autora e organizadora do livro, tem publicado um corpus vasto, rigoroso e acessível, de estudos sobre o fotográfico, entre as ciências da comunicação e a história da arte.

Fotogramas opera o posicionamento da arqueologia dos meios visuais portuguesa no panorama da investigação internacional. Dos seus objetos constam não apenas imagens artísticas, mas arquivos científicos, técnicos, clínicos, vernaculares (Medeiros, 2016, p. 8), cujo valor expositivo contrasta fortemente com os das imagens que os estudos da arte trabalhavam tradicionalmente.

Outro aspeto importante desta publicação reside na sua declarada intenção de entender a dispersão, contradição e fragmentação temáticas e metodológicas dos seus textos como mais-valias - mas também na capacidade de tornar evidente a medida em que tais características constituem, de facto, vantagens científicas.

No seu conjunto, Fotogramas consiste numa atualização da herança da receção de A Câmara Clara (Barthes, 1981), no contexto mais alargado dos Estudos visuais e culturais, depois de Batchen (2009), articulando-a com uma resistência ao paradigma representativo e semiótico que por vezes domina as reflexões sobre a indicialidade. $A$ abordagem cultural dos meios fotográficos é, em geral, aqui bem diferente das nostalgias ou apologias da transparência das imagens que vigoram ainda em muitos outros contextos dos estudos da fotografia e da comunicação.

De assinalar ainda a tradução, a fechar o livro, do essencial texto de Siegfried Kracauer, A Fotografia, de 1927, que antecipa importantes questões teóricas da relação entre fotografia e memória.

Por questões de economia, de entre os textos do livro, demorar-me-ei especialmente nos que vão mais além no esforço de pensar o real enquanto constelação de visíveis, produzindo uma crítica da cultura visual. Preocupar-me-ei não tanto com resumir os capítulos deste livro, mas sobretudo em captar os seus aspetos mais esclarecedores ou as pedras de toque das reflexões que oferecem. 
No enquadramento teórico introdutório à publicação, Margarida Medeiros apresenta uma definição de arquivo como depósito material de tempo, ou uma noção de arquivo como presente ou vida das imagens. Posicionando-se, deste modo, na questão premente da relação entre memória e arquivo, Medeiros destaca a importante ideia de Hal Foster de que as recentes febres do arquivo são essencialmente modos de certificação de que os objetos neles contidos "podem permanecer no presente" (Foster citado em Medeiros, 2016, p. 12). Resulta daqui a distinção entre arquivo (como potência de desordem) e ruína (como decadência da ordem).

A abrir os capítulos de temas individuais, Maria Irene Aparício trata a relação entre fotografia e as crises de memória, entre passado e verdade, no pós-fotográfico, como problemas políticos. Começa por demonstrar que memória, testemunho são conceitos de um entendimento mais representativo e idealista da própria história (do que construtivo), no qual a história é vista como resultado de um processo de mediação de "eventos primordiais" (Aparício, 2016, p. 27). A autora sublinha disforicamente a possibilidade de, na contemporaneidade, aproveitar a falência do paradigma da indicialidade para controlar a ficcionalização da história e a invenção de "imagens de espaços e tempos que só o futuro poderá desocultar" (Aparício, 2016, p. 28).

Maria Augusta Babo conduz uma discussão dos efeitos de subjetividade e da desconstrução da identidade a partir de imagens técnicas como os espelhos, a fotografia e outras operações de registo de imagem. Neste contexto, tematiza o desdobramento ou exteriorização do si, tornado signo, em função da relação a Outro, com recurso a autores como Derrida, Barthes, Lacoue-Labarthe e Didi-Huberman. Isto conduz a autora a uma problematização das imagens virtuais a partir da questão da contiguidade ou da referência como bloqueio de significação.

Maria João Baltazar e Fátima Pombo apresentam uma análise do desejo de neutro, em Barthes, dando a ver que a insatisfação do autor com os usos interpretativos e valorativos da fotografia, vulgarmente associada à obra Câmara Clara, se manifesta também noutros contextos e sob outras formas. Também aqui, Barthes manifesta o desejo de escapar aos paradigmas de receção na linguagem, no sentido de um acesso sem forma e sem "signo tristemente carregado com o seu significado", mas que mantém "sentidos inumeráveis que estalam, crepitam, fulguram" (Barthes citado em Baltazar \& Pombo, 2016, p. 67). Em face da dificuldade ou mesmo impossibilidade de representação no registo fotográfico, que resiste passar a imagem social e significante, de linguagem, as autoras pretendem gerir este paradoxo com recurso à noção de neutro, enquanto perda de medo da imagem indiciária, sem, no entanto, soçobrar de paixão pelo índice.

Susana Lourenço Marques trata o género da fotografia em livro e a entrada, por volta dos anos 1970, da fotografia na tradição do medium literário, nos arquivos e no âmbito autoral e editorial. Pensa, assim, a reinvenção do arquivo fotográfico a partir do estudo de exposições, edições, reedições e recontextualizações na imprensa, ao longo dos anos, do livro Lisboa, Cidade Triste e Alegre, de Victor Palla e Costa Martins. Marques apresenta uma análise profunda das relações entre imagem, texto e contexto que sucessivamente transformam as ressonâncias desta série a partir da reprodução e da 
circulação de um dos seus objetos - de uma das suas fotografias. Singulariza assim gestos capazes de iluminar teoricamente a questão do" valor de exposição" da imagem e produz uma genealogia dos processos técnicos, culturais, semióticos e institucionais que enquadram a distribuição geral dos meios fotográficos nas últimas décadas.

Teresa Castro desenvolve um estudo rigoroso da cultura visual do Atlas científico como dispositivo epistemológico de classificação e disposição - um dos primeiros métodos de resposta à "pulsão arquivística". Este estudo põe em evidência o carácter agregador da estratégia do Atlas na produção de visões de mundo, numa "lógica cumulativa e analítica que conduz o leitor da visão global às imagens parciais, da meditação sobre o universal à contemplação dos detalhes" (Castro, 2016, p. 124). Nesse contexto, a oposição entre os modelos epistemológicos da descrição e da comparação corresponde, em traços largos, à oposição entre antropologia (mais classificatória) e etnografia (mais descritiva). Os atlas surgem aí como objetos problemáticos: em causa está a pobreza etnológica dos usos antropométricos dos meios fotográficos. A autora descreve ciclos de confiança e de desconfiança deste instrumento. A serialidade, platitude e nitidez da fotografia está ligada aos "ideias de exatidão e de clareza" na base de catalogação sistemática, que facilita os estudos comparativos. Por outro lado, o detalhe fotográfico torna-se excessivo para o modelo comparativa tipológico. As "mil diferenças" (Castro, 2016, p. 125) visíveis na fotografia fazem com que esta seja também "colocada ao serviço das descrições etnográficas" (Castro, 2016, p. 125).

Susana Martins elabora, a partir das obras de Joachim Schmid (a quem Fontcuberta chama predador de imagens), uma "crítica das noções de génio, de estilo e de cânone" (Martins, 2016, p. 153) nas práticas artísticas fotográficas. Temas como acaso e aleatoriedade, contra-intencionalidade e re-contextualização ajudam a pensar a criação e curadoria do objet trouvé fotográfico. A reflexão sobre a obra de Joachim Schmid revela-se oportuna para uma comparação entre estas mesmas práticas na era analógica e na era digital e das redes. O "desaparecimento da componente objectual e física da fotografia" (Martins, 2016, p. 149) não impede o artista de continuar a prática de encontrar, de modo mais ou menos acidental, fotografias de outros. Constata-se até que a cultura online do snapshot potencia este tipo de práticas, como é demonstrado pela sua "biblioteca de fotografia popular contemporânea" (Martins, 2016, p. 152), em Other people's photographs, 2008-2011. Aqui se percebe que o digital intensifica uma cultura fotográfica que já vinha a constituir-se, em larga medida, durante o fim do período analógico.

Victor dos Reis tem vindo a desenvolver um importante e singular estudo da experimentação fotográfica de Francisco Afonso Chaves, fotógrafo naturalista. A obra deste fotógrafo revela um questionamento dos conceitos modernos de corpo e espaço, através das práticas (intrigantes no contexto histórico desta produção), em fotografia esteroescópica, de dupla exposição e de exercícios cinemáticos. Estão em jogo a ambivalência entre transparência e opacidade; a dissolução das formas; o contraste entre realidade e ficção ou virtualidade; a imaterialidade ou instabilidade do corpo. Qualquer destes aspetos é revelador da reflexão do fotógrafo sobre este medium. Victor Flores faz uma revisão das mais significativas propostas da arqueologia dos média - em torno de 
autores como Ernst, Huhtamo, Kittler, Crary, Gunning - para o trabalho de descrição e crítica da cultura visual da estereoscopia portuguesa. Este é um estudo paralelo das práticas estereoscópicas e dos discursos em seu redor. Esforço tanto mais importante quanto mais significativo é o apagamento deste medium da história oficial da fotografia, ou quanto esta prática da estereoscopia consiste numa descontinuidade tout court face à cristalização dos meios fotográficos, pretensamente lineares, bidimensionais e transparentes.

No contexto de uma série alargada de importantes estudos do autor sobre a cultura visual da medicina em Portugal, António Fernando Cascais analisa aqui o arquivo de fotografia psiquiátrica do hospital Miguel Bombarda. Trata-se de uma crítica da cultura visual da medicina que realmente está para lá de uma mera "História da Medicina em Imagens". Esta passa pela análise de todo e qualquer "uso médico" de imagens e "dos mundos de sentido que as tornaram necessárias, produtivas, funcionais e inteligíveis" (Cascais, 2016, p. 180). Neste estudo da cultura visual da medicina têm lugar tanto a reflexão sobre o panóptico do Hospital - dispositivo com dupla valência de observatório e de laboratório - quanto a análise do corpus fotográfico dos seus arquivos no contexto da prática da fotografia médica em Portugal, a história da verdade médica como processo de visibilidade e descritibilidade dos fenómenos patológicos ou o estudo dos discursos contemporâneos fundadores desta cultura visual. $\mathrm{O}$ autor oferece um importante contributo para a compreensão dos usos da imagem no contexto geral da medicina experimental moderna - projeto biopolítico de "consequências tanatopolíticas" (Cascais, 2016, p. 190) - alicerçados pela crença na "competência sensória, perceptiva, que (...) permite ver e dar a ver" (Cascais, 2016, p. 198) a loucura ou o crime, em tantos casos indestrinçáveis.

Em conclusão, importa notar que, apesar da referida fragmentação, e quase indisciplina metodológicas e temáticas que esta publicação pretendia refletir, ela constitui no seu conjunto, por um lado, um sintoma coerente e esclarecedor da crise do paradigma representativo e semiótico no contexto da pós-fotografia e, por outro, um posicionamento coerente e rigoroso da investigação sobre fotografia em Portugal no campo vasto da arqueologia dos media e dos estudos visuais que internacionalmente ganham crescente destaque e impacto nas ciências da comunicação. "

\section{REFERÊNCIAS BIBLIOGRÁFICAS}

Aparício, M. I. (2016). "Thanks for the Memories": as imagens depois da fotografia e do cinema. In M. Medeiros (Ed.), Fotogramas. Ensaios sobre fotografia (pp. 25-36). Lisboa: Sistema Solar.

Baltazar, M. J. \& Pombo, F. (2016). O desejo de neutro segundo Roland Barthes: a fotografia e o medo da imago. In M. Medeiros (Ed.), Fotogramas. Ensaios sobre fotografia (pp. 63-80). Lisboa: Sistema Solar.

Babo, M. A. (2016). Do espelho à fotografia: a permanência da imagem. In M. Medeiros (Ed.), Fotogramas. Ensaios sobre fotografia (pp. 53-62). Lisboa: Sistema Solar.

Barthes, R. (1981). A Câmara Clara. Lisboa: Edições 70. 
Batchen, G. (2009). Photography degree zero. Reflections on Roland Barthes's Camera lucida. Cambridge: MIT Press.

Cascais, A. F. (2016). A fotografia psiquiátrica no Hospital Miguel Bombarda: um estudo introdutório. In M. Medeiros (Ed.), Fotogramas. Ensaios sobre fotografia (pp. 179-202). Lisboa: Sistema Solar.

Castro, T. (2016). Uma história material do ver e do saber: antropologia, etnologia e atlas fotográficos na coleção do Museu Quai Branly em Paris. In M. Medeiros (Ed.), Fotogramas. Ensaios sobre fotografia (pp. 119-128). Lisboa: Sistema Solar.

Flores, V. (2016). Materialidades estereoscópicas. A estereoscopia portuguesa e a necessidade de um estudo arqueológico. In M. Medeiros (Ed.), Fotogramas. Ensaios sobre fotografia (pp. 167-178). Lisboa: Sistema Solar.

Marques, S. L. (2016). A fotografia na estante: Lisboa 'Cidade Triste e Alegre' (1956/59-2009). In M. Medeiros (Ed.), Fotogramas. Ensaios sobre fotografia (pp. 91-104). Lisboa: Sistema Solar.

Martins, S. (2016). Quando a fotografia se perde, fotograficamente: a arte pós-fotográfica de Joachim Schmid. In M. Medeiros (Ed.), Fotogramas. Ensaios sobre fotografia (pp. 141-156). Lisboa: Sistema Solar.

Medeiros, M. (2016). A memória de família e a sua fantasmagorização: snapshot, identidade e telepatia na série Re-take of Amrita de Vivan Sundaram. In M. Medeiros (Ed.), Fotogramas. Ensaios sobre fotografia (pp. 11-24). Lisboa: Sistema Solar.

Medeiros, M. (Ed.) (2016). Fotogramas. Ensaios sobre fotografia. Lisboa: Sistema Solar.

Reis, V. dos (2016). O corpo como hipótese: sucessão, sobreposição e transparência em Francisco Afonso Chaves (1857-1926). In M. Medeiros (Ed.), Fotogramas. Ensaios sobre fotografia (pp. 157-168). Lisboa: Sistema Solar.

\section{NotA BiográFicA}

Joana Bicacro é Professora Assistente das disciplinas de Cultura Visual e Metodologias de Análise de Imagem. Mestre em Ciências da Comunicação - Cultura Contemporânea e Novas Tecnologias pela Universidade Nova de Lisboa (FCSH-UNL). Aluna de doutoramento no Centro de Investigação em Comunicação Aplicada, Cultura e Novas Tecnologias (CICANT, ULHT). Encontra-se a desenvolver actividades de investigação em cultura visual, arqueologia dos média e cinema, sendo a sua dissertação dedicada ao tema da viagem virtual na cultura visual contemporânea. Publicou artigos sobre cultura visual, cinema, tecnologias e arqueologia dos média.

E-mail: joana.bicacro@ulusofona.pt

CICANT / ECATI, Universidade Lusófona de Humanidades e Tecnologias, Campo Grande 376, 1749-024 Lisboa, Portugal

\section{* Submetida: 13-11-2017}

* Aceite: 25-11-2017 